\title{
Tin Dioxide Nanocrystals as an Effective Sensitizer for Erbium Ions in Er-Doped $\mathrm{SnO}_{2}$ Systems for Photonic Applications
}

\author{
Tran T. T. Van, ${ }^{1}$ Nguyen Truc Ly, ${ }^{2}$ Le T. T. Giang, ${ }^{1}$ and Cao Thi My Dung1 \\ ${ }^{1}$ University of Science, Vietnam National University Ho Chi Minh City, 227 Nguyen Van Cu Street, Ward 4, \\ District 5, Ho Chi Minh City, Vietnam \\ ${ }^{2}$ Ho Chi Minh City University of Technical Education, 1 Vo Van Ngan Street, Linh Chieu Ward, \\ Thu Duc District, Ho Chi Minh City, Vietnam
}

Correspondence should be addressed to Tran T. T. Van; tttvan@hcmus.edu.vn

Received 27 June 2016; Accepted 24 August 2016

Academic Editor: Jean M. Greneche

Copyright (C) 2016 Tran T. T. Van et al. This is an open access article distributed under the Creative Commons Attribution License, which permits unrestricted use, distribution, and reproduction in any medium, provided the original work is properly cited.

Undoped $\mathrm{SnO}_{2}$ and erbium-doped $\mathrm{SnO}_{2}$ powders were successfully prepared by precipitation method. The effect of the heat treatment and doping contents on the structure of tin oxide and optical properties was also studied. The XRD data and Raman spectra indicate that the $\mathrm{SnO}_{2}$ crystals have formed after being heat-treated at $400^{\circ} \mathrm{C}$ and the average size of grains is about $8 \mathrm{~nm}$ for doping content of $1 \mathrm{~mol} \%$. An increase of doping concentration has controlled the growth of nanocrystals. The principle of the visible and infrared emissions of $\mathrm{SnO}_{2}$ and $\mathrm{SnO}_{2}$ : $\mathrm{Er}$ is also discussed. All photoluminescence study shows that the $\mathrm{Er}^{3+}$ ions can be located in $\mathrm{SnO}_{2}$ nanocrystals and that there is energy transfer from defect levels of $\mathrm{SnO}_{2}$ nanoparticles to neighboring $\mathrm{Er}^{3+}$ ions of crystals.

\section{Introduction}

Erbium-doped semiconductors are considered to be promising optical materials for optoelectronic devices because the emission at $1.54 \mu \mathrm{m}$ of the $\mathrm{Er}^{3+}$ intra-4f shell transition coincides the minimum absorption and dispersion in optical fibers. The incorporation of $\mathrm{Er}^{3+}$ ions in nanocrystals not only prevents the aggregation even at high concentrations but also allows the crystal-ion energy transfer, thus enhancing the efficiency of ion luminescence. The energy transfer from semiconductor nanocrystals to $\mathrm{Er}^{3+}$ ions can efficiently compensate the small cross-section of rare earth transitions. Numerous works have reported the photoluminescent properties of $\mathrm{Er}^{3+}$ ions in different semiconductors host via indirect or direct excitation [1-8].

Tin oxide $\left(\mathrm{SnO}_{2}\right)$ is well-known as an n-type semiconductor with a wide band gap $\left(E_{\mathrm{g}}=3.6 \mathrm{eV}\right.$ at $\left.300 \mathrm{~K}\right)$ and a good host material for rare earth (RE) ions due to its outstanding chemical, optical, electrical, and morphological properties. Moreover, with its very low cutoff phonon energy of $630 \mathrm{~cm}^{-1}, \mathrm{SnO}_{2}$ is prone to reducing the nonradiative decay of multiphonon relaxation of RE ion excited states. Tin oxide nanocrystals can be excited by a broad range of UV radiation wavelengths, as compared to the narrow excitation peaks of the $\mathrm{Er}^{3+}$ ions. Therefore, these nanocrystals can be easily and efficiently excited by broadband arc lamps with UV emission and then they transfer energy to the $\mathrm{Er}^{3+}$ ions.

The aim of our work is focused on optimizing synthesis parameters such as annealing temperature and erbium concentration in order to achieve maximum luminescence of erbium ions in both visible and infrared regions. In this study, emission spectra show more information about the exact location of $\mathrm{Er}^{3+}$ as well as an evidence of efficient energy transfer from $\mathrm{SnO}_{2}$ nanocrystals to erbium ions.

\section{Experimental Technique}

In order to prepare the undoped and $\mathrm{Er}^{3+}$-doped $\mathrm{SnO}_{2}$ nanoparticles, $2 \mathrm{~g}$ of tin chloride was dissolved in $4 \mathrm{~mL}$ ethanol and stirred for 15 minutes. In the latter case, an amount of erbium nitrate $\left(\mathrm{Er}\left(\mathrm{NO}_{3}\right)_{3} \cdot 5 \mathrm{H}_{2} \mathrm{O}\right)$ was dissolved in ethanol and mixed with the solution of tin and stirred for 


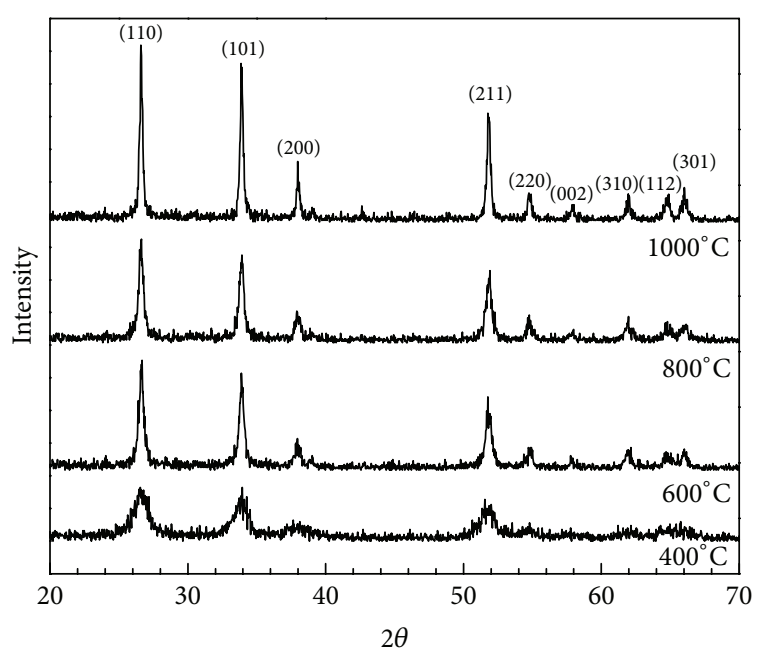

FIGURE 1: XRD patterns of $\mathrm{SnO}_{2}$ doped $1 \% \mathrm{Er}^{3+}$ annealed at different annealing temperatures.

two hours. Aqueous ammonia solution was added dropwise to the above solution and continuously stirred for 30 minutes to form the white precipitates following the reaction:

$$
\mathrm{SnCl}_{2}+2 \mathrm{NH}_{4} \mathrm{OH} \longrightarrow \mathrm{Sn}(\mathrm{OH})_{2}+2 \mathrm{NH}_{4} \mathrm{Cl} \text {. }
$$

These precipitates were filtered and then washed with water and ethanol prior to drying at $55^{\circ} \mathrm{C}$ for 36 hours. The final powders $\left(\mathrm{SnO}_{2}\right.$ and $\mathrm{Er}^{3+}$-doped $\left.\mathrm{SnO}_{2}\right)$ were calcined at different temperatures ranging from $400^{\circ} \mathrm{C}$ to $1000^{\circ} \mathrm{C}$ for 1 hour.

The phases of the samples have been identified by using Bruker D8 diffractometer. The morphology and crystalline size of $\mathrm{SnO}_{2}$ particles have been determined by transmission electron microscopy (TEM). Fourier transform infrared (FTIR) spectroscopy has been performed in the range of $400-4000 \mathrm{~cm}^{-1}$. The Raman spectra have been obtained using Renishaw InVia Raman Microscope system with a $632 \mathrm{~nm}$ excitation wavelength at room temperature. Photoluminescence (PL) has been carried out at room temperature using the wavelength of $300 \mathrm{~nm}$ from Xenon ion laser as the excitation source with a luminescence HORIBA JOBIN YVON iHR320.

\section{Results and Discussions}

\subsection{Structural Properties}

3.1.1. XRD Diffraction. XRD patterns of the $1 \mathrm{~mol} \% \mathrm{Er}^{3+}$ doped samples heat-treated at $400^{\circ} \mathrm{C}$ and $1000^{\circ} \mathrm{C}$ are displayed in Figure 1. The peaks corresponding to tetragonal rutile-type $\mathrm{SnO}_{2}$ (JCPDS code 41-1445) are observed for sample, heat-treated at $400^{\circ} \mathrm{C}$ (the bottom pattern). The intensity evolution of diffraction peaks as a function of annealing temperature indicates an increase of crystallization in the sample. In addition to the peaks characterized for $\mathrm{SnO}_{2}$ rutile phase, no other peaks are observed, which reveals that the dopant is well dispersed in the $\mathrm{SnO}_{2}$ host.

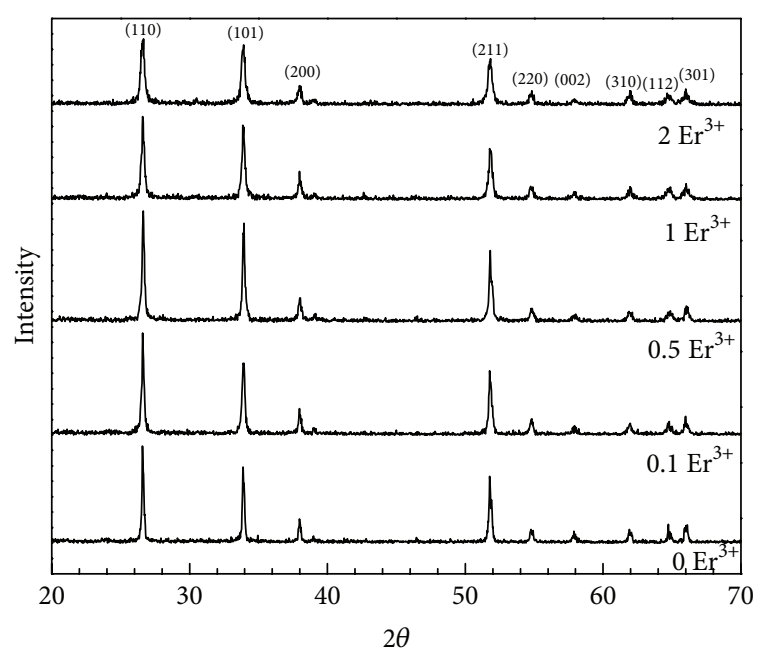

FIGURE 2: XRD patterns of different $\mathrm{Er}^{3+}$ concentrations annealed at $1000^{\circ} \mathrm{C}$.

XRD patterns of samples with different concentrations of $\mathrm{Er}^{3+}$ annealed at $1000^{\circ} \mathrm{C}$ in Figure 2 show a decrease of intensity with the doping contents. This observation implies that the presence of $\mathrm{Er}^{3+}$ ions leads to smaller crystal grains. The ionic radius mismatch of Sn and Er is $28 \%$, where $0.72 \AA$ is of $S n$ and $1.004 \AA$ is of Er. This difference causes the tensile stress into the $\mathrm{SnO}_{2}$ matrix, restricting the growth of particle size. That is the reason of the decrease of grain boundaries with increasing $\mathrm{Er}^{3+}$ ion in host material. The crystallite size has been calculated using the Scherer formula $D=0.9 \lambda /(\beta$. $\cos \theta$ ) where $\lambda=1.54 \AA$ for $\mathrm{Cu} \mathrm{K}_{\alpha}$ radiation, $\beta$ is the full width at half-maximum (FWHM), $\theta$ is the corresponding Bragg angle, and $k$ is a constant taken to be 0.9 .

Calculation from XRD data of powders doped $1 \mathrm{~mol} \% \mathrm{Er}$ shows that the size of crystal increases from $8 \mathrm{~nm}$ for samples annealed at $400^{\circ} \mathrm{C}$ to $34 \mathrm{~nm}$ at $1000^{\circ} \mathrm{C}$. This behaviour indicates the agglomeration and represents the particle size growth under the influence of sintering. The sintering temperature promotes enlargement of grain boundaries and consequently particle size increases as a function of annealing temperature $[2,9]$.

The average size as a function of Er concentrations estimated from XRD data is displayed in Figure 3. The crystallite size decreases gradually from $\sim 50 \mathrm{~nm}$ for undoped samples to $\sim 25 \mathrm{~nm}$ for samples doped with $2 \mathrm{~mol} \% \mathrm{Er}^{3+}$. The TEM images of $0 \%$ and $2 \%$ Er performed in the inset of Figure 3 also prove these results.

3.1.2. Vibrational Spectra. Figure 4 shows the FTIR spectra of $1 \% \mathrm{Er}^{3+}$-doped $\mathrm{SnO}_{2}$ powders heat-treated at different temperatures. For the sample annealed at $400^{\circ} \mathrm{C}$, the bands at 1637 and $3426 \mathrm{~cm}^{-1}$ are associated with the bending and stretching vibrations of $\mathrm{OH}$ groups of some residual water in the powder. The intensity decrease of these bands with the annealing temperatures indicates that the $\mathrm{O}-\mathrm{H}$ groups can be eliminated by a calcination process. The presence of these $\mathrm{OH}$ groups has detrimental effects on optical properties; thus 


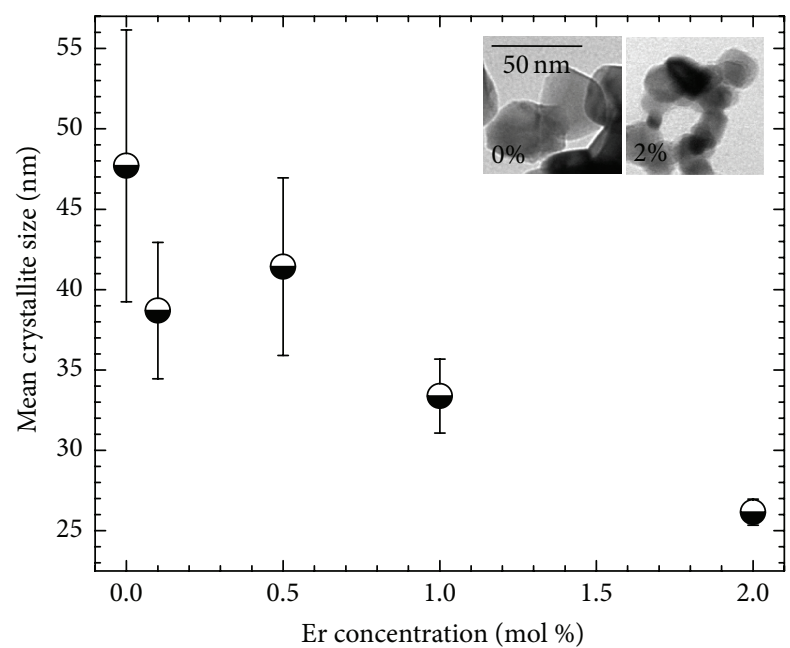

FIGURE 3: Average size particles of $\mathrm{SnO}_{2}$ with different $\mathrm{Er}^{3+}$ concentrations annealed at $1000^{\circ} \mathrm{C}$ and insets are TEM images of $0 \%$ and $2 \% \mathrm{Er}^{3+}$.

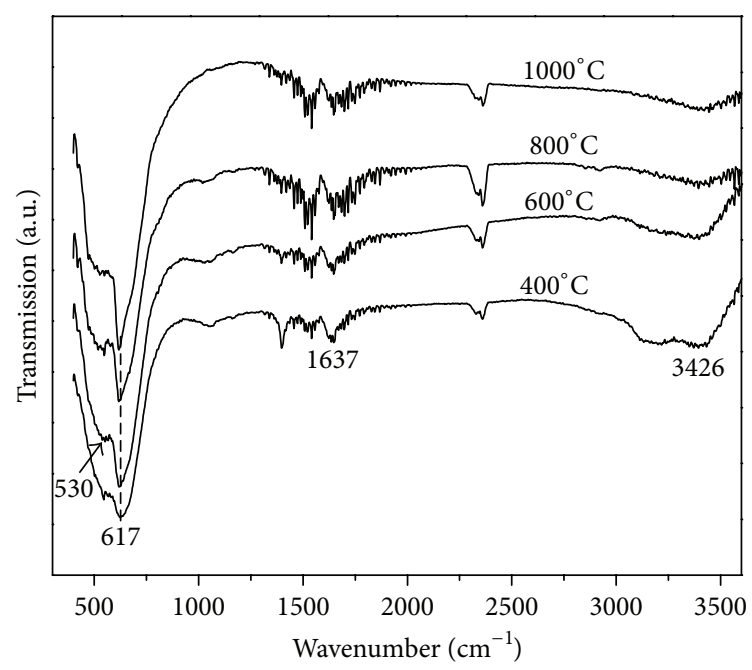

FIGURE 4: FTIR spectra of $1 \%$ Er-doped samples heat-treated at different temperatures.

the samples need to be annealed at temperature as high as $1000^{\circ} \mathrm{C}$. The absorption peak at $2352 \mathrm{~cm}^{-1}$ is due to O-C$\mathrm{O}$ vibrations of $\mathrm{CO}_{2}$ modes. The intense peaks at $1403 \mathrm{~cm}^{-1}$ are assigned to the typical asymmetrical and symmetrical stretching vibrations of $\mathrm{C}-\mathrm{O}$ whereas the double weaker peaks located at $1045 \mathrm{~cm}^{-1}$ are attributed to the $\mathrm{C}-\mathrm{O}-\mathrm{C}$ symmetrical stretching vibrations [10]. The peak appearing at $617 \mathrm{~cm}^{-1}$ is typical of O-Sn-O vibrations of $\mathrm{SnO}_{2}$, which confirms the presence of $\mathrm{SnO}_{2}$ as crystalline phase. The band at $530 \mathrm{~cm}^{-1}$ is attributed to the terminal oxygen vibration of $\mathrm{Sn}-\mathrm{OH}$. These two bands increasing in intensity at higher annealing temperature reflect the growth of nanocrystals. Moreover, the absence of bands related to erbium suggests that these ions were homogeneously dispersed in the host.

The formation of a tetragonal structure of $\mathrm{SnO}_{2}$ was also depicted via Raman spectra. Figure 5 presents the Raman

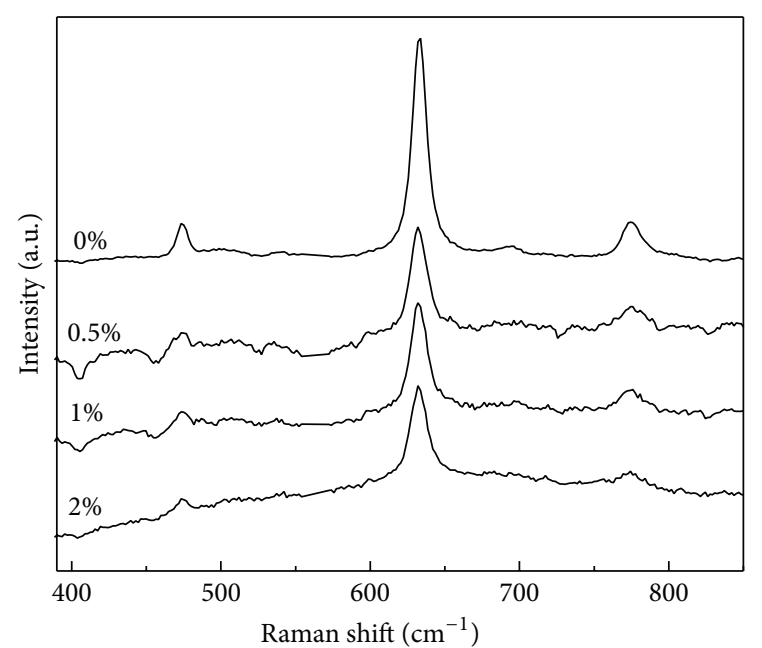

FIGURE 5: Raman spectra of $\mathrm{SnO}_{2}$ doped with different $\mathrm{Er}^{3+}$ concentrations.

spectra as a function of Er content in $\mathrm{SnO}_{2}$ matrix calcined at $1000^{\circ} \mathrm{C}$. The three prominent peaks are observed at 473 , 633 , and $773 \mathrm{~cm}^{-1}$ which are characteristic of rutile $\mathrm{SnO}_{2}$. The scattering peak appearing at $473 \mathrm{~cm}^{-1}$ is attributed to the $E_{\mathrm{g}}$ vibrational modes of $\mathrm{SnO}_{2}$. The highest peak at $633 \mathrm{~cm}^{-1}$ corresponds to the $A_{1 g}$ symmetric $\mathrm{Sn}-\mathrm{O}$ stretching mode in nanocrystalline $\mathrm{SnO}_{2}$ and the peak at $773 \mathrm{~cm}^{-1}$ can be assigned to the $B_{2 g}$ vibrational modes $[7,11,12]$. The intensity evolution of these modes as a function of annealing temperature shows an increase of the volume of crystals. Another feature to be noted here is the decrease in $A_{1 g}$ mode intensity in the Er-doped samples. The reduction of peak intensity suggests that the dopant ions interact strongly with the host, which hinders the crystallization. When the doping concentration increases, the crystallinity decreases. This observation correlates very well with the FTIR, XRD, and TEM data.

3.2. Photoluminescence (PL). The influence of the incorporation of erbium in the tin oxide nanoparticles on luminescence is studied through the photoluminescence measurements of powders with different erbium concentrations. Figure 6 shows the PL spectra under an excitation at $300 \mathrm{~nm}$ of $\mathrm{SnO}_{2}$ powders undoped and doped $0.5 \%, 1 \%$, and $2 \mathrm{~mol} \%$ annealed at $1000^{\circ} \mathrm{C}$. The spectrum divides into two regimes ranging from visible to IR region.

For the pure $\mathrm{SnO}_{2}$ sample (the bottom spectrum), a large emission intensity around $620 \mathrm{~nm}$ is observed. This band can be attributed to the defect states energy level of $\mathrm{SnO}_{2}$ nanocrystals. These defect states may originate from oxygen vacancies produced in the annealing process because the organic species would consume oxygen. In the studies of Bonu et al. [13, 14], they have showed that there are two types of "O" vacancies in the $\mathrm{SnO}_{2}$ crystals which are bridging oxygen $\left(\mathrm{O}^{\mathrm{B}}\right)$ and in-plane oxygen $\left(\mathrm{O}^{\mathrm{P}}\right)$ vacancies. Yellow luminescence $(\mathrm{YL})(\sim 620 \mathrm{~nm})$ is attributed to the 


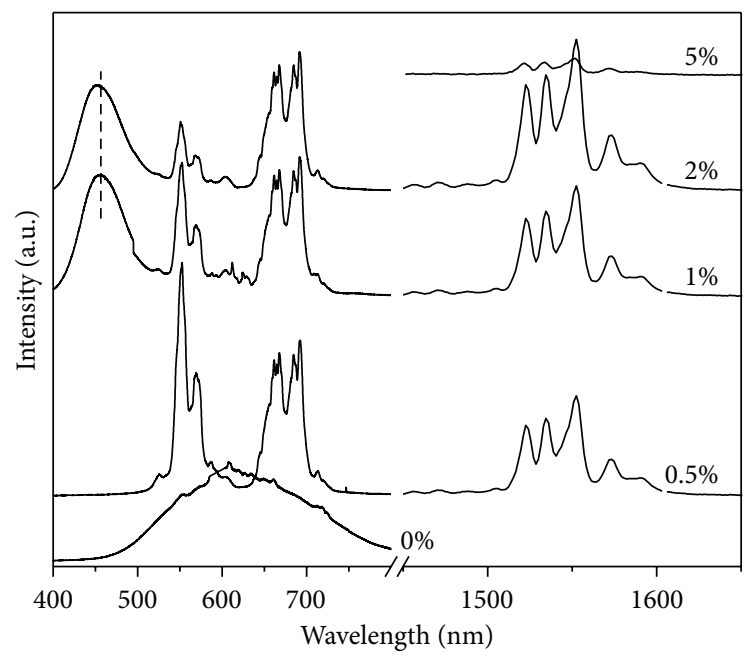

FIGURE 6: PL spectra with different $\mathrm{Er}^{3+}$ concentrations under excitation of $300 \mathrm{~nm}$ after annealing at $1000^{\circ} \mathrm{C}$.

defect states created by $\mathrm{O}^{\mathrm{B}}$ vacancies whereas the bluegreen luminescence (BGL) is due to $\mathrm{O}^{\mathrm{P}}$ vacancies. Thus, it is obvious that the broad emission centred at $620 \mathrm{~nm}$ in this case results from $\mathrm{O}^{\mathrm{B}}$ vacancies. With the slight erbium doping concentration of $0.5 \mathrm{~mol} \%$, we obtain only the narrow characteristic emission peaks at $526 \mathrm{~nm}, 551 \mathrm{~nm}$, and $665 \mathrm{~nm}$ of $\mathrm{Er}^{3+}$ ions due to the transition from ${ }^{2} \mathrm{H}_{11 / 2},{ }^{4} \mathrm{~S}_{3 / 2}$, and ${ }^{4} \mathrm{~F}_{9 / 2}$ level to ${ }^{4} \mathrm{I}_{15 / 2}$ level, respectively. However, a new emission band at $454 \mathrm{~nm}$ appears in the spectra of $1 \%$ and $2 \mathrm{~mol} \% \mathrm{Er}^{3+}$. The substitution of $\mathrm{Er}^{3+}$ in $\mathrm{Sn}^{4+}$ sites leads to the formation of acceptor states above the valence band of $\mathrm{SnO}_{2}$ due to the lack of 1-charge. Hence the emission at $454 \mathrm{~nm}$ is the result of recombination of electron from conduction band to these acceptor centres. The intensity of this emission increases with doping contents and this band shifts to shorter wavelength due to the fact that an increasing of doping concentration not only induces the more acceptor centres but also shifts the acceptor levels nearer to the valence band [15]. The disappearance of characteristic band at $620 \mathrm{~nm}$ of $\mathrm{SnO}_{2}$ in all spectra of doped samples proves that the energy is efficiently transferred from defect levels of $\mathrm{SnO}_{2}$ nanocrystals to $\mathrm{Er}^{3+}$ ions.

The presence of narrow bands at 1521, 1531, 1549, and $1571 \mathrm{~nm}$ in infrared region is assigned to the Stark transitions between ${ }^{4} \mathrm{I}_{13 / 2}$ and ${ }^{4} \mathrm{I}_{15 / 2}$ levels of erbium ions. When the erbium ion occupies the $\mathrm{Sn}^{4+}$ sites in the cassiterite structure, the electrostatic field of the surrounding environment of ions removes degeneracy of the free ion J levels and makes them split into doubly degenerated Stark levels [16-18]. Upon an indirect excitation at $300 \mathrm{~nm}$, this emission results from energy transfer between $\mathrm{SnO}_{2}$ nanoparticles and the rare earth ions. The well-resolved sharp Stark-splitting peaks in ${ }^{4} \mathrm{I}_{13 / 2} \rightarrow{ }^{4} \mathrm{I}_{15 / 2}$ emission in Figure 6 suggest that a significant portion of $\mathrm{Er}^{3+}$ ions was incorporated inside a crystalline phase of the host nanoparticles in these Erdoped $\mathrm{SnO}_{2}$ samples. With increasing erbium concentration, the near-infrared emission intensity at $1540 \mathrm{~nm}$ is steadily enhanced. The PL intensity of the $2 \mathrm{~mol} \%$ Er-doped sample is increased by a factor of about 1.5 compared to that of the $0.5 \mathrm{~mol} \%$ Er-doped one. However, a noticeable decrease in emission intensity of $5 \mathrm{~mol} \%$ Er-doped system indicates that quenching of luminescence has occurred with this doping content.

\section{Conclusions}

In conclusion, $\mathrm{Er}^{3+}$-doped $\mathrm{SnO}_{2}$ nanoparticles were successfully prepared using the precipitation method with an appropriate heat treatment process. The $\mathrm{SnO}_{2}$ crystal size increases with annealing temperature and is controlled by doping concentration. A heat treatment at $1000^{\circ} \mathrm{C}$ is necessary in order to optimize the emission in both visible and infrared regions though the crystal size ranges from $25 \mathrm{~nm}$ to $40 \mathrm{~nm}$. The decrease of particle size accompanies the sharp emission peaks of $\mathrm{Er}^{3+}$ ions and the appearance of emission at $450 \mathrm{~nm}$ indicates that $\mathrm{Er}^{3+}$ ions were incorporated in $\mathrm{SnO}_{2}$ sites. The correlation between luminescence intensity in both visible and infrared regions and doping concentration was demonstrated. All the observations from PL measurements strongly suggest that energy is efficiently transferred from $\mathrm{SnO}_{2}$ defect levels to the $\mathrm{Er}^{3+}$ ions. The emission intensity at $1540 \mathrm{~nm}$ is found to be maximum for an Er doping concentration of $2 \mathrm{~mol} \%$ and then decreases for higher concentrations of Er, which could be attributed to the concentration quenching. The emission at $1540 \mathrm{~nm}$ of erbium ions is useful for optical-fiber communication due to the low loss as well as the minimum noise and high gain for this wavelength. The special optical features of these systems make them promising candidates for photonic applications like solar concentrators, green or NIR emitters, and optical amplifiers.

\section{Competing Interests}

The authors declare that there is no conflict of interests regarding the publication of this paper.

\section{Acknowledgments}

This research is funded by Vietnam National Foundation for Science and Technology Development (NAFOSTED) under Grant no. 103.03-2015.34.

\section{References}

[1] Z. Pan, "Photoluminescence of Er-doped $\mathrm{ZnO}$ nanoparticle films via direct and indirect excitation," Journal of Nanophotonics, vol. 6, no. 1, Article ID 063508, 2012.

[2] R. R. Gonçalves, Y. Messaddeq, M. A. Aegerter, and S. J. L. Ribeiro, "Rare earth doped $\mathrm{SnO}_{2}$ nanoscaled powders and coatings: enhanced photoluminescence in water and waveguiding properties," Journal of Nanoscience and Nanotechnology, vol. 11, no. 3, pp. 2433-2439, 2011.

[3] T. S. Atabaev, "Concentration-dependent optical properties of erbium doped zirconia nanocrystals," American Journal of Nano Research and Applications, vol. 2, no. 1, pp. 13-16, 2014. 
[4] X. Wang, X. Kong, G. Shan et al., "Luminescence spectroscopy and visible upconversion properties of $\mathrm{Er}^{3+}$ in $\mathrm{ZnO}$ nanocrystals," The Journal of Physical Chemistry B, vol. 108, no. 48, pp. 18408-18413, 2004.

[5] S. Sambasivam, S. B. Kim, J. H. Jeong et al., "Effect of $\mathrm{Er}^{3+}$ doping in $\mathrm{SnO}_{2}$ semiconductor nanoparticles synthesized by solgel technique," Current Applied Physics, vol. 10, no. 6, pp. 1383-1386, 2010.

[6] L. P. Ravaro, A. Tabata, J. B. B. Oliveira, and L. V. A. Scalvi, "Raman and photoluminescence of $\mathrm{Er}^{3+}$-doped $\mathrm{SnO}_{2}$ obtained via the sol-gel technique from solutions with distinct $\mathrm{pH}$," Optical Materials, vol. 33, no. 1, pp. 66-70, 2010.

[7] E. A. D. Morais, L. V. A. Scalvi, A. A. Cavalheiro, A. Tabata, and J. B. B. Oliveira, "Rare earth centers properties and electron trapping in $\mathrm{SnO}_{2}$ thin films produced by sol-gel route," Journal of Non-Crystalline Solids, vol. 354, no. 42-44, pp. 4840-4845, 2008.

[8] A. Moadhen, C. Bouzidi, H. Elhouichet, R. Chtourou, and M. Oueslati, "Concentration and temperature dependence of visible up-conversion luminescence in sol-gel $\mathrm{SnO}_{2}$ doped with erbium," Optical Materials, vol. 31, no. 8, pp. 1224-1227, 2009.

[9] A. Gaber, M. A. Abdel- Rahim, A. Y. Abdel-Latief, and M. N. Abdel-Salam, "Influence of calcination temperature on the structure and porosity of nanocrystalline $\mathrm{SnO}_{2}$ synthesized by a conventional precipitation method," International Journal of Electrochemical Science, vol. 9, pp. 81-95, 2014.

[10] H. Chen, L. Ding, W. Sun, Q. Jiang, J. Hu, and J. Li, "Synthesis and characterization of $\mathrm{Ni}$ doped $\mathrm{SnO}_{2}$ microspheres with enhanced visible-light photocatalytic activity," RSC Advances, vol. 5, no. 69, pp. 56401-56409, 2015.

[11] L. Tan, L. Wang, and Y. Wang, "Hydrothermal synthesis of $\mathrm{SnO}_{2}$ nanostructures with different morphologies and their optical properties," Journal of Nanomaterials, vol. 2011, Article ID 529874, 10 pages, 2011.

[12] S. K. Pillai, L. M. Sikhwivhilu, and T. K. Hillie, "Synthesis, characterization and photoluminescence properties of $\mathrm{Dy}^{3+}$ doped nano-crystalline $\mathrm{SnO}_{2}$," Materials Chemistry and Physics, vol. 120, no. 2-3, pp. 619-624, 2010.

[13] V. Bonu, A. Das, A. K. Prasad, N. G. Krishna, S. Dhara, and A. $\mathrm{K}$. Tyagi, "Influence of in-plane and bridging oxygen vacancies of $\mathrm{SnO}_{2}$ nanostructures on $\mathrm{CH}_{4}$ sensing at low operating temperatures," Applied Physics Letters, vol. 105, no. 24, Article ID 243102, 2014.

[14] V. Bonu, A. Das, S. Amirthapandian, S. Dhara, and A. K. Tyagi, "Photoluminescence of oxygen vacancies and hydroxyl group surface functionalized $\mathrm{SnO}_{2}$ nanoparticles," Physical Chemistry Chemical Physics, vol. 17, no. 15, pp. 9794-9801, 2015.

[15] V. Mangalam, K. Pita, and C. Couteau, "Study of energy transfer mechanism from $\mathrm{ZnO}$ nanocrystals to $\mathrm{Eu}^{3+}$ ions," Nanoscale Research Letters, vol. 11, article 73, 2016.

[16] R. Maâlej, M. Dammak, S. Kammoun, and M. Kammoun, “Theoretical investigation of a single erbium center in hexagonal gallium nitride," Journal of Luminescence, vol. 126, no. 2, pp. 695-701, 2007.

[17] E. A. Morais, S. J. L. Ribeiro, L. V. A. Scalvi et al., "Optical characteristics of $\mathrm{Er}^{3+}-\mathrm{Yb}^{3+}$ doped $\mathrm{SnO}_{2}$ xerogels," Journal of Alloys and Compounds, vol. 344, no. 1-2, pp. 217-220, 2002.

[18] X. Wang, X. Kong, Y. Yu, Y. Sun, and H. Zhang, "Effect of annealing on upconversion luminescence of $\mathrm{ZnO}: \mathrm{Er}^{3+}$ nanocrystals and high thermal sensitivity," The Journal of Physical Chemistry C, vol. 111, no. 41, pp. 15119-15124, 2007. 

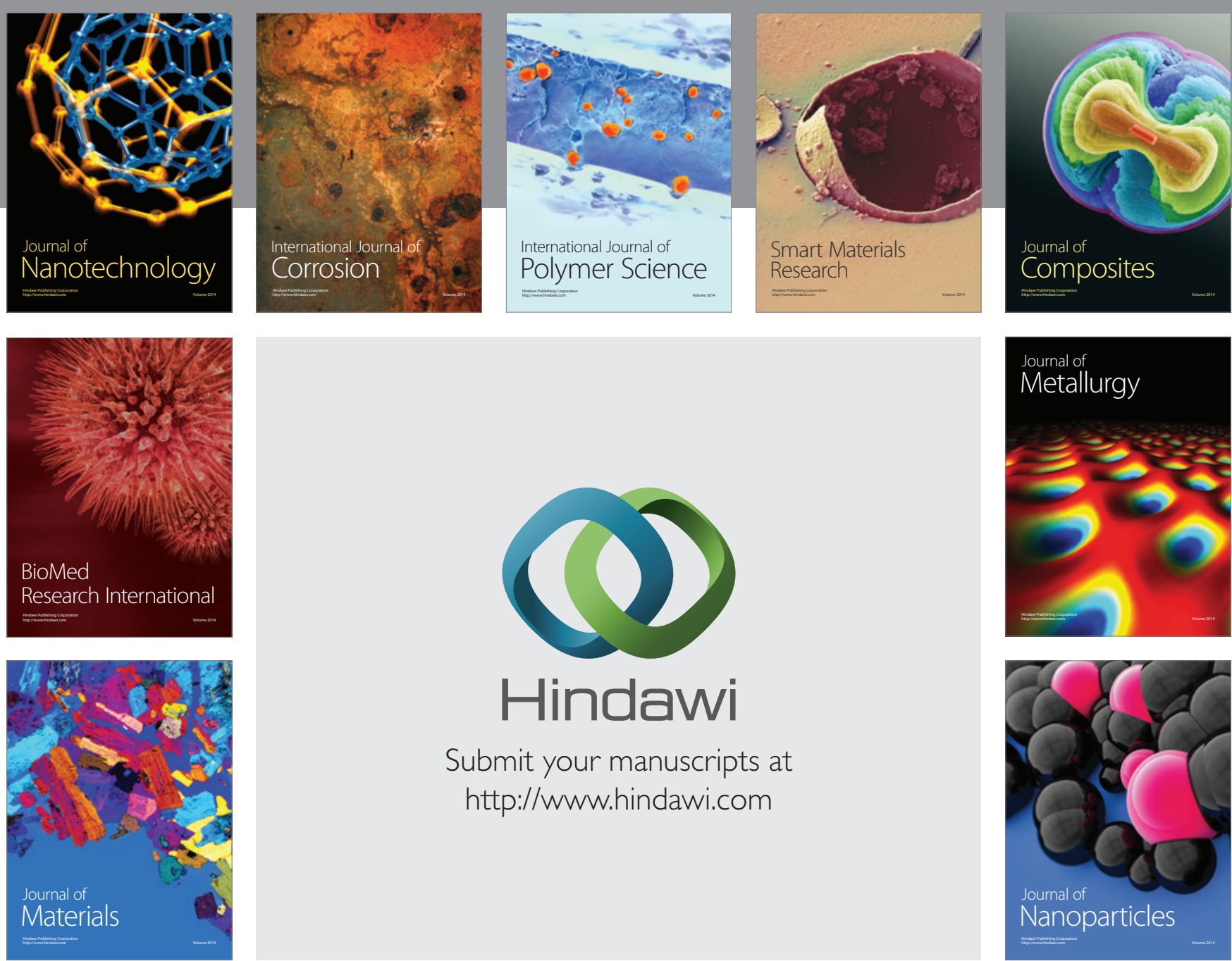

\section{Hindawi}

Submit your manuscripts at

http://www.hindawi.com

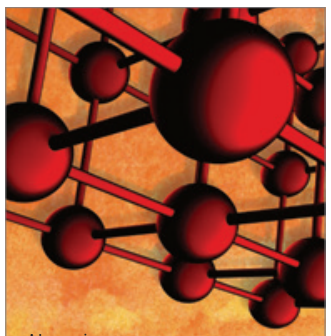

Materials Science and Engineering
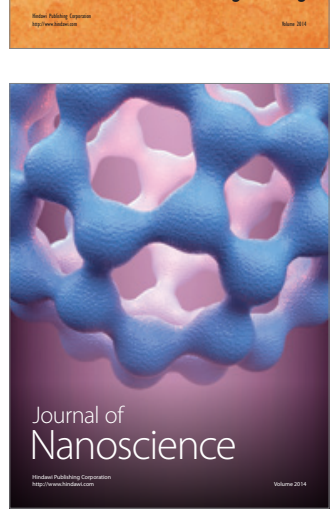
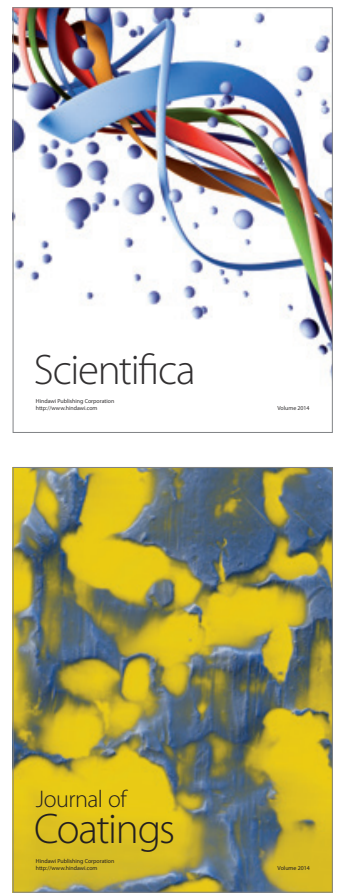
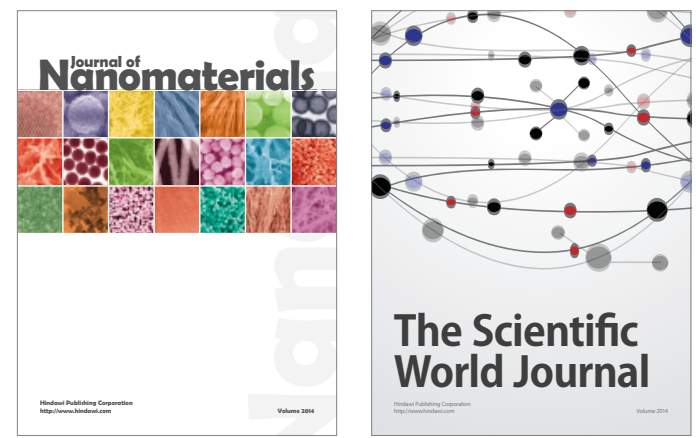

The Scientific World Journal
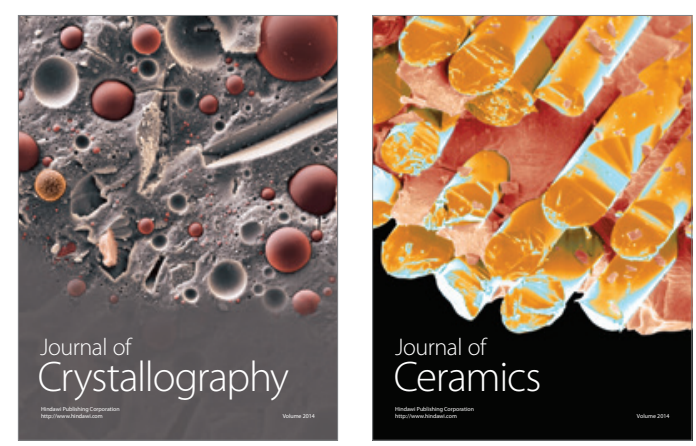
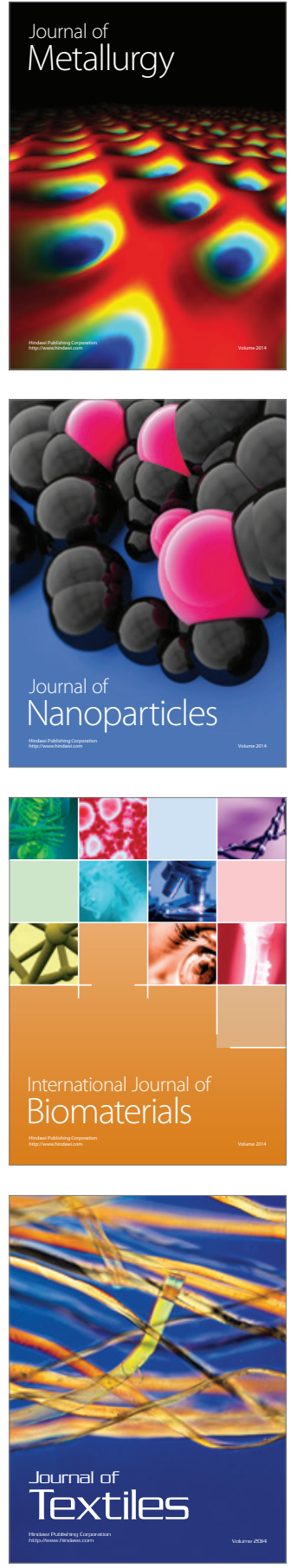